\title{
Effects of obesity surgery (laparoscopic sleeve gastrectomy technique) on lower urinary tract symptoms, depression and quality of life of males: Prospective study
}

\author{
Fatih Uruç $^{1}$, Serkan Akan ${ }^{1}$, Bekir Aras ${ }^{2}$, Çağlar Yıldırım ${ }^{1}$, Aytaç Şahin ${ }^{1}$, Ozgur Haki Yuksel ${ }^{1}$, \\ Mehmet Timuçin Aydın ${ }^{3}$, Ayhan Verit ${ }^{1}$ \\ ${ }^{1}$ Department of Urology, Fatih Sultan Mehmet Research and Training Hospital, Istanbul, Turkey; \\ ${ }^{2}$ Department of Urology, Dumlupınar University, Evliya Çelebi Research and Training Hospital, Kütahya, Turkey; \\ ${ }^{3}$ Department of General Surgery, Fatih Sultan Mehmet Research and Training Hospital, Istanbul, Turkey.
}

\begin{abstract}
Summary Purpose: Technically, obesity weakens the pelvic base muscles by causing an increase in the intraabdominal pressure and intravesical pressure due to increasing fat and it triggers the occurrence of lower urinary tract symptoms. However it is believed that weight loss will cause recovery of these symptoms. Our purpose in this study is to research about the effects of the weight loss achieved by using especially the Laparoscopic Sleeve Gastrectomy (LSG) technique of bariatric surgery which is being more and more widely used today.

Materials and Methods: Out of all patients who had LSG surgery due to obesity earlier in our center during the period between April 2014 and March 2015, 22 applicable male patients were considered after a brief exclusion criteria application. Age, height, weight, and body mass index (BMI) data of these patients were recorded before the operation. International Prostate Symptom Score (IPSS), International Consultation on Incontinence Questionnaire - short from) (ICIQ-SF), Beck depression inventory (BECK) and Short form - 36 (SF-36) were filled for the patients and the data were recorded. Also, the weight loss amounts and BMI decreases of the patients after the operation were recorded.

Results: After the procedure, the decrease in the averages of BECK depression inventory, IPSS, ICIQ-SF and the increase in the Mental and Physical subgroup scores of SF-36 were found statistically coherent.

Conclusion: The adverse effect of obesity, which is observed more and more often in today's world, on lower urinary tract symptoms and on the quality of life is undeniable. In our study, we think that the bariatric surgery made by using the LSG technique, not only causes serious amount of weight loss, but also reduces urinary dysfunction and enhances the quality of life among males.
\end{abstract}

KEY WORDS: Obesity; Lower urinary system; Bariatric surgery; Sleeve gastrectomy; Quality of life.

Submitted 12 April 2016; Accepted 22 May 2016

\section{INTRODUCTION}

Obesity is one of the most important health problems in both developing and developed countries today because of the diseases it brings with it. The number of people with obesity has nearly doubled since the year 1980 .
According to the data of World Health Organization (WHO), it is detected that 1.6 billion adults are overweight. And among these individuals, approximately 300 million females are obese $(1,2)$. While $67 \%$ of the population of United States of America (USA) are classified either as obese or overweight, in many European countries, this ratio is around 40-50\% (3). According to the data of 2011, over 40 million of children under 5 years old are overweight $(1,2)$. It is known that there are approximately 500 million obese adults and that this number is on the rise. Approximately 2,8 people a year dies as a result of being overweight or obesity(4). Obesity prevalence was found to be $22.3 \%$ in the Obesity Prevalence Study (TURDEP) in Turkey, in 1997 (5). In the TURDEP II study that was conducted in 2010, the obesity rate in Turkey was found to have increased to $32 \%$. This striking fast increase is alarming (6).

While weight loss can be achieved with non-surgical methods, it was observed that $66 \%$ of these patients reached their former weight in a time period as short as 24 months. The compatibility that the patient will have with the diet during the medical treatment application might form an idea about the patient's compatibility with post-operational treatment. Surgical treatment of morbid obesity stands out due to its possibility of causing deaths as a results of additional diseases and becoming epidemic (7). Today, bariatric surgery is the most effective treatment modality that causes $15 \%$ or more weight loss than the normal procedure (8). Taking mortality, morbidity, cost, patient satisfaction and most importantly the expected weight loss rate into consideration, laparoscopic sleeve gastrectomy (LSG) is one of the most preferred surgical procedures today ( 9 , 10). More than 220.000 bariatric surgical procedures are applied in a year in USA (11). Technically, obesity weakens the pelvic base muscles by causing increase in the intra-abdominal pressure and intravesical pressure due to fattening increase and triggers the lower urinary tract symptoms (LUTS). It is believed that weight loss will cause recovery of these symptoms (12-14).

Our purpose in this study is to research about the effects of the weight loss achieved by using especially the Laparoscopic Sleeve Gastrectomy (LSG) technique of 
bariatric surgery which is being more and more widely used today, on the LUTS and quality of life of males.

\section{Material AND METHOD}

Twenty-two male patients who has LSG surgery due to obesity between April 2014 and March 2015 were taken into study. The patients who met the exclusion criteria below, were excluded from the study.

Exclusion criteria's were: (I) the patient being unwilling, (II) the patient having a known mental or psychiatric disease, (III) the patient having had any surgical or unsurgical weight loss treatment earlier, (IV) the patient having had any surgical procedures for incontinence or any medical treatment due to LUTS earlier, (V) the patient being under the age of 18, (VI) the patient having any respiratory system diseases (COPD) or any neurological diseases that can be related to urinary symptoms.

Twenty-two male patients who met the criteria above were taken under study and the data were evaluated in preoperational and post-operational periods. Age, height, weight, and body mass index (BMI) data of these patients were recorded pre-operation International Prostate Symptom Score (IPSS), International Consultation on Incontinence Questionnaire - short from) (ICIQ-SF), Beck depression inventory (BECK) and Short form - 36 (SF-36) were filled for the patients and the data were recorded. Also, the weight loss amounts and BMI decreases of the patients post-operation were recorded.

IPSS: It is a scoring system originally named as American urology association symptom score and it consists of 8 questions. 0-7 points means mildly symptomatic, 8-19 points mean average symptomatic and 20-35 points means severely symptomatic condition. Severity and progression on a certain period of time of symptoms are compared.

ICIQ-SF: It enables measuring of the severity of incontinence symptoms and its effects on quality of life. The scoring system that consists of 4 questions, is evaluated between 0-21 points. BECK Depression inventory: It is a 21 multiple choice question self-evaluating inventory that is applied to children and adults to measure the severity of anxiety. 0-21 points is evaluated as mild anxiety, 22-356 points is evaluated as average anxiety, 36-63 points is evaluated as severe anxiety.

SF-36: It is a reliable, valid and very often used standard in evaluating the quality of life. Scale consists of 36 subjects and these ensures the measurement of 8 dimensions. These are; vitality (energy), physical function, pain, general health physical, emotional and social role restrictions, mental health. Scoring is summed up in 2 topics that are PCS: physical component summary and MCS: Mental component summary.

\section{Surgery technique}

The patients were operated using LSG technique. Operations were conducted by general surgeons. Sleeve gastretomy (SG) first started to be applied as the restrictive component of the Duodenal Switch operation first. This method was taken into practical use as a risk reducing method in the patients who are at high risk and who may not be able to tolerate long term procedures (15). LSG became a more often used, safe and efficient pri- mary bariatric surgical method that is highly popular among the surgeons and the patients (16). After the large curvature is freed from $2-3 \mathrm{~cm}$ proximal of pylorus up to the angle of HIS (incisura cardiaca), stomach resection is practiced. Posterior dissection is applied by making angle of HIS visible so as not to leave a large fundus pouch. Bending of the stomach from incisura angularis is prevented by fixating the sleeve tube by stitching the omentum or gastrocolic fat. LSG has become a very often preferred method alone or alongside the other methods in treatment of morbid obesity (17).

Statistical Analysis: The study was planned as a prospective study. While evaluating the findings obtained during the studyi IBM SPSS Statistics 22 (IBM SPSS, Turkey) program was used fort he statistical analyses. The compatibility of the parameters to the normal range was evaluated with Shapiro Wilks test during the evaluation of the study data. Along with the definitive statistical methods (average, standard deviation) while evaluating the study data, student $t$ test was used in comparisons between two groups of parameters that Show normal distribution in the comparison of quantitative data, Mann Whitney U test was used in comparison between two groups of parameters that don't Show normal distribution. Pairedsample t test was used in the same group comparison of parameters that Show normal distribution and Wilcoxon sign test was used in the same group comparison of parameters that don't Show normal distribution. Pearson correlation analysis was used in analyzing the relations between parameters that are compatible with normal distribution. Coherence was evaluated at $\mathrm{p}<0.05$ level.

\section{RESULtS}

The study was conducted with 22 male cases that had LSG between the dates April 2014 and March 2015. The ages of the cases vary between 24 and 51 years and the average of the ages is $34.59 \pm 8.07$ years. Statistically meaningful decrease is detected in the average post-operative BMI values, body weight, scores of IPSS and BECK depression inventory in comparison with the post-operative values (for all of them $\mathrm{p}=0.001 ; \mathrm{p}<0.01$ ). Statistically meaningful increases are observed in the PCS and MCS' of the individuals when pre-operative values are compared to the post-operative ones (for all $\mathrm{p}=0.001 ; \mathrm{p}<0.01$ ) Statistically meaningful decrease was detected in ICIQ-SF between pre-operation and post-operation averages $(\mathrm{p}=$ $0.002 ; \mathrm{p}<0.01$ ) (Table 1). There is positive correlation at $62.8 \%$ level observed between post-operative BMI change ratio and post-operative IPSS change ratio when compared with the pre-operative values $(\mathrm{p}=0.002 ; \mathrm{p}<0.01)$. No statistically meaningful correlation was shown between post-operative BMI change ratio and post-operative BECK depression inventory and ICIQ-SF parameters change ratio when compared with the pre-operative values (for all $\mathrm{p}>0.05$ ). There is no meaningful correlation between pre-operative and post-operative BMI change amount and age ( $>$ > 0.05) (Table 2).

\section{Discussion}

According to the data of NHNES (National Health and 
Table 1.

Evaluating post-operation data compared to the pre-operation data of the study parameters in males.

\begin{tabular}{|c|c|c|c|}
\hline & $\begin{array}{c}\text { Pre-operation } \\
\text { Avg } \pm S D \text { (median) }\end{array}$ & $\begin{array}{c}\text { Post-operation } \\
\text { Avg } \pm S D \text { (median) }\end{array}$ & \\
\hline BMI & $49.57 \pm 6.21$ & $38.98 \pm 5.51$ & $10.001 * *$ \\
\hline Weight & $149.73 \pm 21.34$ & $118.23 \pm 19.13$ & $10.001 * *$ \\
\hline IPSS & $4.5 \pm 2.22(5)$ & $1.91 \pm 1.48(2)$ & $20.001 * *$ \\
\hline ICIQ-SF & $1.82 \pm 2.15(1)$ & $0.32 \pm 0.95(0)$ & $20.002^{* *}$ \\
\hline BECK & $15.36 \pm 2.4(15.5)$ & $9.55 \pm 2.09(9)$ & $20.001 * *$ \\
\hline$\overline{P C S}$ & $34.5 \pm 8.13$ & $42.95 \pm 4.95$ & $10.001 * *$ \\
\hline MCS & $40.92 \pm 6.48$ & $46.71 \pm 6.48$ & $10.001 * *$ \\
\hline
\end{tabular}

\section{Table 2.}

Post-operation BMI change in comparison with preoperation and evaluation of the relations between changes in parameters.

\begin{tabular}{|lcc|}
\hline $\begin{array}{l}\text { Post-operation changes } \\
\text { in comparison with pre-operation }\end{array}$ & \multicolumn{2}{l|}{ BMI percentage change } \\
\hline Age & $\mathbf{~ r ~}$ & $\mathbf{p ~}$ \\
\hline IPSS & -0.076 & 0.736 \\
\hline ICIQ-SF & 0.628 & $0.002 * *$ \\
\hline BECK & 0.324 & 0.142 \\
\hline${ }^{1}$ Paired Samples Test; ${ }^{2}$ Wilcoxon Sign Test; ${ }^{* *} p<0.01$. & 0.298 \\
\hline
\end{tabular}

Fif.1 - Overall quality of life of Males.

[IPSS: İnternational Prostate Symptom Score - ICIQ-SF: İnternational consultation on incontinence questionnaire short form - BECK: Beck depression scale - PCS: Physical summary scores - MCS: Mental summary scores. Series 1: Pre-Gastrectomy - Series 2: Post-Gastrectomy]

Nutrition Examination Survey) it is noted that $35.5 \%$ of the males above the age of 20 are obese (BMI $\geq 30 \mathrm{~kg} / \mathrm{m}^{2}$ ) and $73.9 \%$ of them are either overweight or obese (BMI $\geq 25 \mathrm{~kg} / \mathrm{m}^{2}$ ). Metabolic syndrome (MS) is a disease that has a multifactorial component that causes insulin resistance whereas its mechanisms are not completely known (18). While MS incident is $42 \%$ among individuals at 70 years of age and above, it is $6,7 \%$ among the individuals of younger ages between 20-29 years (19).

Epidemiological and clinical data show that obesity, physical activity and nutrition are changeable risk factors for benign prostate hyperplasia (BPH) and LUTS (20).

Although the pathophysiological mechanisms that cause LUTS in obesity are not completely known, many hypotheses were claimed. In many studies, it was shown that obese males have larger prostates that can cause obstruction and consequently LUTS (21). An important correlation was found between metabolic syndrome and yearly prostate volume increase (22). Adipose tissue releases the aromatase enzymes that cause androgens turn into estrogens. It is claimed that prostate growth is lead by the hyperplasia in the prostatic tissue associated with the increase of estrogen/testosterone that originates from the testosterone turning into estrogens in the adipose tissue in obese males (23). Adipocytes cause cytokine release. Some researchers think that, as a consequence of the occurrence of systemic inflammation or oxidative stress in metabolic syndrome, cytokines are released to cause LUTS (24).
In another study, it is argued that in obesity with the increased sympathetic nervous system activation, increased irritative LUTS are caused by contraction of the prostatic muscle component (25).

However in an experimental animal study, it is shown that apoptosis occurs in the neural cells that are exposed to hyperglycemia for a long time causing an increase in LUTS as a result of autonomic hyperactivity with respect to the parasympathetic system (26).

As seen above, many hypotheses were put forward about the relation between obesity and LUTS and many studies were conducted on this relationship in the recent years. The results of a 10 year study of 5926 patients, conducted in USA, show that severe LUTS could be prevented at the rate of $20 \%$ in males who preserved their normal weight (27). Again, Mondul et al. indicated that the total and abdominal fattening increase is a serious risk factor to develop or increase LUTS severity in males and that it is an important target in prevention and treatment of LUTS (28). In a study of 7318 patients, Penson et al. indicated that decreasing physical activity causes an increase in LUTS severity in males that are in normal weight, without taking race into account (29). Again, in a study on the effect of obesity on urine storage symptoms, which was conducted in 2013 with 6000 participants, it was reported that a strong relation exists between obesity and frequency of micturition in males (30). Antithetically to the studies above, Demir et al. and Yee at al. declared that they did not find any relation between LUTS and abdominal obesity (31). However they detected that weight loss causes recovery in LUTS (32). Luke et al. evaluated LUTS of the patients using IPSS demonstrating that there is improvement in LUTS after weight loss, although this was not correlated with the degree of the weight loss or the duration of the weight loss (33).

Pre-operation IPSS average was found to be $4.5 \pm 2.22$ in our study in which the average age is $34.59 \pm 8.07$; 19 of our total 22 male patients were mildly symptomatic (0-7 points) pre-operation, 3 of them were in the average symptomatic group with 8-19 points. Post-operation IPSS average was evaluated as $1.91 \pm 1.48$ and this decrease was found to be statistically significant. When compared with the pre-operation values, a positive correlation at $62.8 \%$ level is observed in post-operation BMI change rates and post-operation IPSS change rates. In our study, in order to measure the severity and the effects of incontinence symptoms on the quality of life, the patients were evaluated with ICIQ-SF form pre-operation and post-operation. Incontinence was not observed in 14 patients out of 22 patients (63\%) in the pre-operation evaluation. In our study, while it was observed that both pre-operation and post-operation incontinence rates are relatively low, the post-operation decrease observed in ICIQ-SF average was found to be statistically significant. Effects of obesity on depression and quality of life for male patients was also evaluated in our study with BECK depression inventory and SF-36 form. Average score of BECK depression inventory was evaluated as low anxiety preoperation with $15.36 \pm 2.4$ point; it has shown improvement by decreasing in the post-operation period. In the study that was conducted in Turkey in 2010, on the effect of the rheumatoid arthritis disease on the patient's overall 
quality of life average PCS in the control group was found 51.28 and MCS was found 41.43 (34). However in our study the average post-operation PCS in the obese patients was measured as 34.5 and MCS as 40.92 that were lower than the population average. Post-operation PCS and MCS scores significantly increased to 42.9 and 46.7 .

\section{Conclusion}

The negative effect of gradually increasing obesity on LUTS and the quality of life is undeniable in today's World. We think that while bariatric surgery helps weight loss in serious amounts, it also decreases the urinary dysfunction in males and increases their quality of life.

\section{References}

1. WHO Factsheet No311.

2. Çitak Akbulut G, Özmen MM, Besler HT. Obesity the disease of the era. TUBITAK Science and Technical Magazine March 2007: 1.

3. World Health Organization. WHO global database on body mass index.

4. World Health Organization. Obesity and Overweight. Available at http://www.who.int/mediacentre/factsheets/fs311/en/ [accessed 28 Sept 2012]

5. Satman I, Yilmaz T, Sengul A, et al. Population-based study of diabetes and risk characteristics in Turkey: results of the Turkish diabetes epidemiology study (TURDEP). Diabetes care. 2002; 25:1551-6.

6. Satman I, Omer B, Tutuncu Y, et al. Twelve year trends in the prevalence and risk factors of diabetes and pre diabetes in Turkish adults. Eur J Epidemiol. 2013; 28:169.

7. Sjostrom L, Narbro K, Sjostrom D, et al. Effects of bariatric surgery on mortality in Swedish obese subjects. N Engl J Med. 2007; 357:741.

8. Colquit JL, Picot J, Loveman E, et al. Surgery for obesity. Cochrane Database Syst Rev. 2009; 2:CD003641.

9. Dixon JB, le Roux CW, Rubino F, Zimmet P. Bariatric surgery for type 2 diabetes. Lancet. 2012; 379:2300.

10. Buchwald H, Oien DM. Metabolic/bariatric surgery worldwide 2011. Obes Surg. 2013; 23:427.

11. Taylor K. Bariatric surgery fact sheet. American Society for Metabolic and Bariatric Surgery web site. Available at http//www.asbs.org/Newsite07/medialasmbs_fs_surgery.pdf. [accessed February 23, 2011]

12. Bai SW, Kang JY, Rha KH, et al. Relationship of urodynamic parameters and obesity in women with stress urinary incontinence. $J$ Reprod Med. 2002; 47:559.

13. Han MO, Lee NY, Park HS. Abdominal obesity is associated with stress urinary incontinence in Korean women. Int Urogynecol J Pelvic Floor Dysfunct. 2005; 17:35.

14. Wasserberg N, Haney M, Petrone P, et al. Morbid obesity adversely impacts pelvic floor function in females seeking attention for weight loss surgery. Dis Colon Rectum. 2007; 50:2096.

15. Brethauer SA, Hammel JP, Schauer PR. Systematic review of sleeve gastrectomy as staging and primary bariatric procedure. Surg Obes Relat Dis. 2009; 5:469.

16. Brethauer SA. Sleeve gastrectomy. Surg Clin N Am. 2011; 91:1265.

17. Mason EE, Ito C. Gastric bypass in obesity. Surg Clin North Am. 1967; 47:1345-51.

18. Hammarsten J, Hogstedt B. Hyperinsulinaemia as a risk fact or for developing benign prostatic hyperplasia. Eur Urol. 2001; 39:151.
19. Ford ES, Giles WH, Dietz WH. Prevalence of the metabolic syndrome among US adults: findings from the third National Health and Nutrition Examination Survey. JAMA 2002; 287:356.

20. Raheem OA, Parsons JK. Associations of obesity, physical activity and diet with benign prostatic hyperplasia and lower urinary tract symptoms. Curr Opin Urol. 2014; 24:10.

21. Muller RL, Gerber L, Moreira DM, et al. Obesity is associated with increased prostate growth and attenuated prostate volume reduction by dutasteride. Eur Urol. 2013; 63:1115.

22. Glynn RJ, Campion EW, Bouchard GR, Silbert JE. The development of benign prostatic hyperplasia among volunteers in the Normative Aging Study. Am J Epidemiol. 1985; 121:78.

23. Parsons JK, Sarma AV, McVary K, Wei JT. Obesity and benign prostatic hyperplasia: clinical connections, emerging etiological paradigms and future directions. J Urol. 2009; 182:27.

24. Furukawa S, Fujita T, Shimabukuro M, et al. Increased oxidative stress in obesity and its impact on metabolic syndrome. J Clin Invest. 2004; 114:1752.

25. Giovannucci E, Rimm EB, Chute CG, et al. Obesity and benign prostatic hyperplasia. Am J Epidemiol. 1994; 140:989.

26. Cellek S, Rodrigo J, Lobos E, et al. Selective nitrergic neuron degeneration in diabetes mellitus a nitric oxide-dependent phenomenon. Br J Pharmacol. 1999; 128:1804.

27. Flegal KM, Carroll MD, Kit BK, et al. Prevalence of obesity and trends in the distribution of body mass index among US adults 19992010. JAMA. 2012; 307:491.

28. Mondul AM, Giovannucci E, Platz EA. A prospective study of obesity, and the incidence and progression of lower urinary tract symptoms. J Urol. 2014; 191:715.

29. Penson DF, Munro HM, Signorello LB, et al. Urologic Diseases in America Project. Obesity, physical activity and lower urinary tract symptoms: results from the Southern Community Cohort Study. J Urol. 2011; 186:2316.

30. Vaughan CP, Auvinen A, Cartwright R, et al. Impact of obesity on urinary storage symptoms: results from the FINNO study. J Urol. 2013; 189:1377.

31. Demir O, Akgul K, Akar Z, et al. Association between severity of lower urinary tract symptoms, erectile dysfunction and metabolic syndrome. Aging Male. 2009; 12:29.

32. Yee CH, So WY, Yip SK, et al. Effect of weight reduction on the severity of lower urinary tract symptoms in obese male patients with benign prostatic hyperplasia: a randomized controlled trial. Korean J Urol. 2015; 56:240-6; discussion 246.

33. Luke S, Addison B, Broughton K, et al. Effects of bariatric surgery on untreated lower urinary tract symptoms: a prospective multicentre cohort study. BJU Int. 2015; 115:466.

34. Kirgiz C, Senel Ö, Sever O, Arslanoglu E. Observing the quality of life of the training personnel that are working in physical education and sports departments. Kafkas Educational Research Magazine 1(1), April 2014.

\section{Correspondence}

Fatih Uruç, MD (Corresponding Author) - urucmd@gmail.com

Fatih Sultan Mehmet Research and Training Hospital, Department of Urology Içerenkoy/Atasehir, Tr- 34752 Istanbul, Turkey

Serkan Akan - drserkanakan@gmail.com

Bekir Aras - bekiraras1@gmail.com

Çağlar Yildırım - C_yildirim_87@hotmail.com

AytaçSahin - draytacsahin@gmail.com

Ozgur Haki Yuksel - Yuksel:ozgurhaki@gmail.com

Mehmet Timuçin Aydın - mtimucina@gmail.com

Ayhan Verit-veritayhan@yahoo.com 